\title{
ZORRILLA Y SU CONCEPTO DEL «TIEMPO NUEVO» (LECTURA DE LA POESÍA DE SUS ÚLTIMOS AÑOS)
}

\author{
Marta Palenque
}

1. «... voy a escribir algunas historias que parecen novelas y algunos cuentos que son historias; todo ello tan descosido, tan ilógico, tan destartalado y fantástico como mi vieja poesía; pero acaso más útil, más trascendental y más de mi tiempo, lo cual será curioso, porque manifestará que, habiendo vivido entre vejeces y sido narrador de viejas historias en mi juventud, entro, viejo verde, en la corriente del tiempo nuevo en mi vejez, y me preparo a morir vestido a la última moda y según el último figurín...

Huye, pues, de mí, espíritu, inspiración entusiasta y creyente de mi poesía juvenil, vuélvete al cielo, de donde viniste musa cristiana mía, que no naciste en el Parnaso ni en la Castalia fuente bebiste, y deja a mi lado al olímpico bufón, semidiós pagano y representante bufo de nuestro desvergonzado positivismo, para morirme riendo con él de lo que he vivido cantando y glorificando» (Recuerdos del tiempo viejo. Tomo I, págs. 309 y 310) ${ }^{1}$.

2. En 1854 José Zorrilla embarcaba con destino a Méjico. Se iniciaba así una larga ausencia de tierras españolas: no regresaría hasta 1866. Su estancia en América puede ser utilizada para marcar un límite en el total de su producción literaria. En el terreno teatral el escritor vivirá casi sólo de las rentas: acude a numerosos reestrenos de sus más populares obras dramáticas y sólo compone, con posterioridad a 1866, el drama Pilatos (1877) y convierte en zarzuela el Don Juan Tenorio (1877). Crea un mayor número de obras líricas y épico-líricas al mismo tiempo que vuelve a publicar, o utiliza en sus lecturas públicas, versos de años anteriores a su salida de España. En esta poesía última ofrece una serie de temas constantes, casi obsesivos, podríamos decir, por la frecuencia con que se repiten

1 Los Recuerdos del tiempo viejo se publicaron por primera vez en artículos en El Imparcial (1879). Citamos por la edición de Publicaciones Españolas, Madrid, 1961. 
en los diferentes textos ${ }^{2}$ : el enfrentamiento entre el «tiempo viejo» (el pasado tradicional-español pero también el pasado romántico) y el «tiempo nuevo» (el realista) es su base.

La estancia del poeta en el continente americano coincide con años decisivos en la evolución de la poesía en nuestro país. Los años comprendidos entre 1840 y 1860 son importantes en la transición del romanticismo al realismo. A lo largo de estas décadas se hace evidente el descontento de los autores con respecto al romanticismo y la sensación de caos demandaba un cambio ${ }^{3}$. Son propuestas varias soluciones en el terreno poético que podemos considerar el inicio de las líneas que se desarrollarán en el período realista. José Selgas, Antonio Arnao, Ventura Ruiz Aguilera, Ramón de Campoamor, Gabriel García Tassara, ..., indican posturas diferentes en la renovación del hecho poético pero, conjuntamente, un deseo de adaptación a los nuevos tiempos. Se reaccionará frente a la poesía vacía y retórica; frente a la excesiva fantasía, alejamiento y evasión románticos. Se evoluciona hacia una lírica concisa, de expresión directa en cuanto a la forma, trascendente y real en cuanto al fondo.

La relación entre la poesía y la sociedad se torna cada vez, y necesariamente, más estrecha. Una frase de la Poética campoamorina (de 1879) resume el ideario de la época: «No se puede vivir en un tiempo y respirar en otro» ${ }^{4}$. El poeta no podía, ni debía - opinan los autores del momento-, mantenerse al margen de los acontecimientos que se sucedían en la realidad más inmediata. Gaspar Núñez de Arce:

« ¿Los tiempos son de lucha! ¿Quién concibe el ocio muelle en nuestra edad inquieta?

En medio de la lid canta el poeta, el tribuno perora, el sabio escribe» ${ }^{5}$.

Tanto Campoamor como Núñez de Arce, representantes de dos de las líneas fundamentales de la lírica realista, abogan por esa poesía enlazada a la realidad de su tiempo. En cuanto a la forma, eligen soluciones diferentes, aunque coinci-

2 Con posterioridad a 1866 Zorrilla publica las siguientes obras en verso: Álbum de un loco (1867), El drama del alma. Algo sobre México y Maximiliano (1867), Ecos de las montañas (1868), un tomo de Lecturas públicas hechas en el Ateneo científico y literario de Madrid y en el teatro Jovellanos en 1877 (contiene versos anteriores a esta fecha ya publicados con anterioridad), La leyenda del Cid (1882), ¡Granada mía! Lamento muzárabe (1885; luego contenido en Gnomos y mujeres), El cantar del romero (1886), Gnomos y mujeres (1886), ;A escape y al vuelo! (1888), De Murcia al cielo (1888), Mi última brega. Los rincones de Valladolid (1888), La leyenda de Don Juan Tenorio (1895). Puede añadirse su «Discurso de recepción en la Real Academia de la Lengua» (1885). Otros poemas suyos aparecieron en diversos periódicos o fueron sólo difundidos a través de las lecturas públicas. Véanse los recogidos en Últimos versos no coleccionados (1908) y la edición de Poesías realizada por Narciso Alonso Cortés (1925). Estos volúmenes constituyen la bibliografía esencial de nuestro trabajo.

3 Sobre estos años véase el libro de Salvador García: Las ideas literarias en España entre 1840 y 1850, University of California Press, 1971.

4 Aunque publicada en 1883, el núcleo de esta Poética fue leído por Campoamor en el Ateneo madrileño en marzo de 1879. Cito por la edición de Victoriano Suárez, Madrid, 1883, pág. 77.

5 Del poema «Introducción» que abre Gritos del combate, Madrid-Sevilla, Librería de Fe-Hijos de Fe, 1880 (2.), pág. 1. La primera edición es de 1875. 
den en destacar la importancia de la idea y la comprensión del contenido. Gustavo Adolfo Bécquer, pese a mantener temas y motivos de procedencia romántica (al igual que otros poetas de su línea), dejaba también clara su elección en el comentario a La soledad de su amigo Augusto Ferrán: desprecia la poesía pomposa y llena de oropeles y se queda con la breve, concisa y natural ${ }^{6}$.

José Zorrilla pertenecía por edad y por concepción al período romántico. Es el poeta del entierro de Larra, el cantor del pasado legendario y fantástico, el creador de castillos y torres misteriosas, de góticos salones. Poeta de instinto y no de ciencia, compara su poesía con el canto de las aves. En uno de sus últimos poemas se refería en estos términos a su obra de juventud:

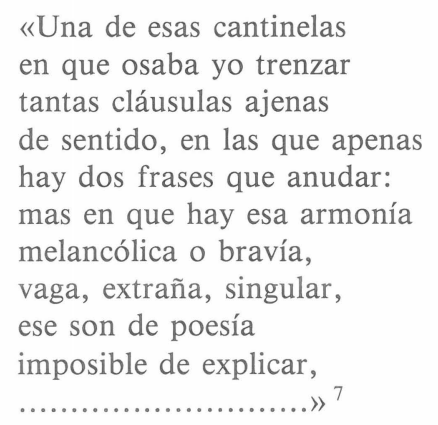

$\mathrm{Su}$ característica formal más destacada había sido la exuberancia, el dominio del verso que degeneraba en muchas ocasiones en palabrería; dato notorio, sobre todo, en su poesía lírica. Recordemos a este respecto las indicaciones de Ramón de Campoamor, quien en El Personalismo (1855) señalaba que había decidido seguir en su obra el camino del pensamiento y la poesía filosófica e íntima porque Zorrilla se había reservado la parcela correspondiente a la objetiva y todos los atributos de la extensión. En otros lugares Campoamor se sitúa, de la misma manera, enfrentado a la poesía zorrillesca y aconseja a las nuevas generaciones que eludan «las flores» con que éste la «asfixia» si quieren avanzar hacia una nueva, basada en el buen gusto ${ }^{8}$.

Cuando Gustavo Adolfo Bécquer se refiere a «la poesía magnífica y sonora;... que se engalana con todas las pompas de la lengua,...», para preferir la «natural, breve, seca», o cuando Núñez de Arce declaraba la inoportunidad de ciertas formas poéticas: «esas arcaicas reproducciones, frías como el retrato de un muerto, de nuestros tiempos gloriosos y caballerescos, con sus galanes pendencieros, sus damas devotas y libidinosas y su ferviente misticismo entreverado de citas y

6 Puede verse en Rimas y declaraciones poéticas. Edición de Francisco López Estrada, Madrid, Espasa-Calpe («Selecciones Austral»), 1977, pág. 256.

7 «Lectura hecha en la escena del teatro Zorrilla, de Valladolid en la noche de su inauguración, el 31 de octubre de 1884», en Almanaque de La Ilustración Española y Americana para 1886, pág. 123.

8 Así se lo señalaba al poeta Guillermo Belmonte Müller en 1874. Carta citada por Vicente Ortí Belmonte: «Centenario del nacimiento del poeta Guillermo Belmonte Müller», en Boletín de la Real Academia de Córdoba, de Ciencias, Bellas Letras y Nobles Artes, núm. 67, enero a junio de 1952, pág. 191. 
cuchilladas» ${ }^{9}$ están negando formas de poesía enlazadas con el pasado romántico. Podríamos describir la lírica de Zorrilla en los mismos términos: claramente es un autor comprendido en esta reacción.

En sus Recuerdos del tiempo viejo advertimos cómo el poeta vallisoletano conocía los cambios producidos en el palenque literario español y temía que, a su vuelta, se le considerase un poeta anacrónico y fuese, en consecuencia, rechazado:

«Los mejicanos me habían pronosticado que mi patria no se acordaba de mí; yo me había ya apercibido, por las obras nuevas que había ojeado, de que la nueva pléyade literaria de España, la juventud sobre todo, sabía más que yo, porque había estudiado más; lo que se escribía tenía más meollo y menos hojarasca que con la que yo había afiligranado mis huecos versos» ${ }^{10}$.

La actitud humilde que observamos en esta cita será una constante en muchas de sus declaraciones de estos años.

Los estudiosos de la obra poética zorrillesca han coincidido en señalar el intento de adaptación a la lírica realista que realizó el poeta tras su regreso a España. Ricardo Navas Ruiz lo relaciona con la crisis de conciencia que sufrió con motivo del fusilamiento de Maximiliano y puede ser ejemplificada en la crítica y el inconformismo de alguno de sus últimos poemas. Pero Zorrilla, también insiste en ello Navas, es siempre el mismo: el concepto de la poesía que mantiene hasta el final es romántico aunque se acerque al realismo o al simbolismo en algunos de sus versos ${ }^{11}$. José María de Cossío, quien criticaba muy duramente esta etapa de la producción zorrillesca, era terminante a este respecto:

«Pasa sobre esta época de poesía naturalista como un pájaro sobre las aguas, sin mojar ni una siquiera de sus plumas» ${ }^{12}$.

Zorrilla intentó acercarse a la nueva poesía, superficialmente al menos. Así, escribió poemas filosóficos al estilo de Campoamor y Núñez de Arce («La inteligencia», contenida en Álbum de un loco, «Pulvis es», dedicado al último de los poetas mencionados,...). En otras composiciones, y por el tono expresivo utilizado, se aproxima igualmente al realismo. Sin embargo, la actitud que muestra el autor hacia éste, del que salva algunos nombres, y con respecto a la sociedad de la época en general, es siempre negativa.

En parte, el prosaísmo de estos últimos poemas puede ser explicado por su carácter de «poeta profesional» ${ }^{13}$. Zorrilla escribía movido por necesidades económicas. El tema de una composición le venía dado por la ciudad que debía visi-

9 Cita de Bécquer, véase la nota 6. Núñez de Arce: «Prefacio» a Gritos del combate, obra citada, pág. XXIII.

10 Obra citada, tomo II, págs. 249-50.

11 Ricardo Navas Ruiz: El romanticismo español, Madrid, Cátedra, 1982, pág. 314.

12 Cincuenta años de poesía española (1850-1900). Tomo I, Madrid, Espasa-Calpe, 1960, págs. 11-12.

13 Así lo llama Juan Luis Alborg: Historia de la literatura española. Tomo IV, Madrid, Gredos, 1980, pág. 562 . 
tar o por la dama a la que debía halagar. El quería, ante todo, permanecer en el candelero y obtener, más que gloria, beneficios económicos ${ }^{14}$. Esto explica mejor su deseo de adaptarse a los nuevos tiempos.

Zorrilla era muy sensible a las críticas y sale en su poesía siempre al paso de ellas, justificándose y defendiéndose continuamente. En «La mandrágora», después de pasar revista a su obra de juventud, exclama:

$$
\begin{aligned}
& \text { "¿Creéis que va a ser más útil } \\
& \text { que nuestro romanticismo } \\
& \text { vuestro audaz positivismo } \\
& \text { sin fe, vergüenza ni afán? } \\
& \text { ¿Creéis que va comprendida } \\
& \text { a ser jamás en España } \\
& \text { vuestra jerga, esa maraña } \\
& \text { de flamenco y de alemán? }{ }^{15} \text {. }
\end{aligned}
$$

El poeta parece cansarse de la soberbia de los críticos de la nueva generación que consideran al romanticismo, y a su propia obra, pasadas y superadas y le piden que se retire. Utilizando diferentes modos expresivos convierte la poesía de sus últimos años en una prolongación y recuerdo continuo del «tiempo viejo».

3. En los textos publicados a partir de 1866, Zorrilla se presenta a sí mismo con títulos tales como «trovador vagamundo del siglo XIX», «trovador romántico», «hidalgo del tiempo viejo»,...; en definitiva, «un poeta de ayer» que no puede sino seguir viviendo del pasado:

$$
\begin{aligned}
& \text { "Yo soy viejo y ya no valgo } \\
& \text { lo que dicen que valía», } \\
& \text { "... que envejezco y que mi tiempo } \\
& \text { pasó ya y que yo pasé» }{ }^{16} \text {. }
\end{aligned}
$$

Con repetida frecuencia alude a su vejez, a su pertenencia al pasado. Ya en 1880 estaba escribiendo sus memorias (los Recuerdos del tiempo viejo) y sus últimas composiciones no serán otra cosa.

Dos argumentos utiliza el poeta, junto al de la edad, para justificar su necesidad de volver al pasado y su dificultad en adaptarse al presente: su falta de ciencia y su locura. Él es poeta de la generación de los pájaros y no de la de los sabios

14 Sus necesidades económicas llegaron llegaron a ser apremiantes. En carta a Esteban López Escobar escribía que temía acabar en la cárcel a causa de sus muchas deudas. Si es sorprendente la actividad que el poeta desarrolla durante estos años, sus cartas hacen ver que le cansaba y aburría gran parte de esta actividad. Son interesantes las epístolas contenidas en Zorrilla comentador póstumo de sus biógrafos. Cartas íntimas e inéditas del gran poeta español (1883-1889), recogidas y prologadas por Francisco Rodríguez Marín, Madrid, G. Bermejo impresor, 1934.

15 Apéndice del libro Gnomos y mujeres, Madrid, Librería de F. Fe, 1886, pág. 254.

16 Fragmentos de «Recuerdo del tiempo viejo», poema leído en su coronación (celebrada en Granada en 1889). Recogido con otros textos leídos por el poeta en este acto en Coronación de Don José Zorrilla, Madrid, Fuentes y Capdeville, 1889, pág. 21; y «Nosce te ipsum» publicado en Revista Contemporánea, en 1878, y recogido por Narciso Alonso Cortés en Poesías, Madrid, Eds. «La Lectura», 1925, págs. 163-164. 
o filósofos. Decía en su «Discurso de recepción en la Real Academia Española de la Lengua» (pronunciado en 1885):

«Yo no hago versos ya: los que di al pueblo

alzar al sol le hicieron la cabeza,

y los poetas de hoy en nuevo rumbo

del progreso social a entrar le enseñan.

Los poetas de ayer éramos pájaros,

hoy filósofos son, casi profetas:

yo embelesé a mi pueblo con gorjeos,

los de hoy el sol del porvenir le muestran» ${ }^{17}$.

En Álbum de un loco (1867) ya señalaba que su poesía no intentaba «ni ense$\tilde{n} a r$, ni corregir» ${ }^{18}$. Él es un poeta de escasa ciencia, la suya no es una poesía de ideas, repite en varias ocasiones:

«Yo soy el escritor de menos ciencia,

el ingenio español menos profundo,

el versificador más sin conciencia» ${ }^{19}$.

Un autor que no enseña, que no es «útil al bien social», como se exige a la generación realista, dice Zorrilla en el discurso señalado anteriormente, no puede sino refugiarse en el pasado al que pertenece:

«voy, pues del pasado vivo,

de lo pasado a ampararme»,

indicaba al iniciar el poema «Recuerdo del tiempo viejo» ${ }^{20}$.

El siguiente argumento: su locura. Ello explica por qué un poeta que nada puede enseñar se atreve a escribir en los nuevos tiempos:

«Mas yo nací hablador y soy fanático

por ensuciar papel: no es que presuma

de sabio, de doctor, ni catedrático;

yo no soy más que un loco, soy lunático;

es un defecto natural; y en suma,

sin darla de orador ni de retórico,

cuando ya mi cerebro está pletórico,

reviento por la lengua y por la pluma.

Con que, lector, los sesos no te hiles

en suponerme ocultas intenciones

ni literarias y altas pretensiones,

ni miras diplomáticas u hostiles».

17 «Discurso leído por el Excmo. Sr. D. José Zorrilla en el solemne acto de su recepción oficial en la Academia Española, el domingo 31 de mayo de 1885», en La Ilustración Española y Americana, núm. 21, 8 de junio de 1885, págs. 334-35.

18 De la «Introducción y prospecto», Madrid, Alonso Gullón editor, 1867, pág. 18.

19 «Est Deus in nobis», en Coronación de Don José Zorrilla, citada, pág. 33.

20 «Recuerdo del tiempo viejo», en Coronación..., citada, pág. 240. 
«YO ME ECHO A ESCRIBIR; PORQUE ESTOY LOCO» repite, y con mayúsculas, evitando cualquier confusión ${ }^{21}$.

Juega siempre Zorrilla entre el no poder y el no querer adaptarse al progreso y a los nuevos tiempos. Gusta de cotejarlos con los viejos para concluir que las distancias son insalvables. En su opinión, la poesía romántica era «mágica»; la realista, prosaica vulgaridad.

La crítica que ejerce sobre el período realista, el «tiempo nuevo», puede resumirse en dos puntos:

1) El progreso y la ciencia amenazan con destruir la fe del hombre. Lo positivo mata la poesía como la máquina destruye la naturaleza. Visión negativa de los resultados obtenidos a causa del progreso a lo largo del siglo.

2) Su poesía es la POESÍA frente a la no poesía o a la prosa puesta en verso, como llama a la realista o naturalista. Defensa del verso. Pérdida de interés del público por él.

Zorrilla se hace eco de varias de las polémicas entabladas durante el siglo en relación con la poesía. En ellas, como veremos, su actitud es siempre negativa para los nuevos tiempos.

La desconfianza del poeta vallisoletano hacia el progreso y la ciencia es anterior a 1866 e independiente, en un primer momento, de la crítica al realismo. Más tarde se convertirán en una misma cosa.

Zorrilla se suma a los autores conservadores que consideran el avance científico como una amenaza para la vida del hombre pues, cree, acaba con sus más íntimas creencias. El convencimiento de la imposibilidad de un proceso paralelo en los campos de la ciencia y el espíritu produce este rechazo. En Cuentos de un loco (1853) el poeta se pregunta si la soberbia humana llegará tan lejos que Dios morirá a manos de la ciencia. Desprecia al que llama «siglo de la luz»y dice preferir la recreación del pasado en sus versos como una forma de mantenerse puro y fuerte en su fe católica:

«Oye tu historia como yo la veo

bajo distinta faz, a luz distinta

de a las que el sempiterno cacareo

de tus gárrulos sabios nos la pinta.

Llámante el siglo de la luz; yo creo

que eres, según se escribe, el de la tinta:

que eres el siglo de fósforos y globos,

sólo siglo de luz para los bobos.

Siglo de la banal caricatura,

estéril forjador de teorías,

21 Álbum de un loco, citado, pág. 10. Otra de las obsesiones de la obra zorrillesca, sobre todo en esta última época, es el tema de la locura. Varias de sus obras lo utilizan como recurrencia. Por un lado, es el concepto de la locura romántica unido al tópico, tan utilizado en la literatura española; por otro, se trata de una enfermedad real para el poeta: Zorrilla tenía varios tumores en la cabeza. Una operación para estirpárselos le produjo la muerte. En varios lugares relacionó su enfermedad con la locura que, decía, regía su obra. En este caso el tópico se ve apoyado por la realidad personal del autor. 


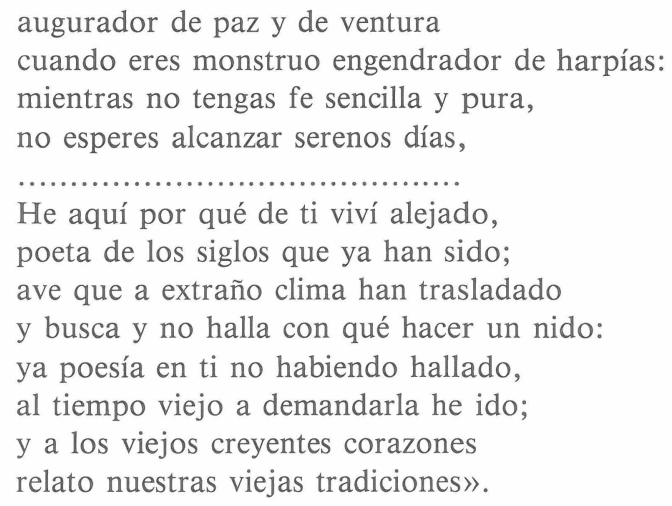

«Dios es la ciencia», termina el poema ${ }^{22}$. El siglo canta la «omnipotencia del saber», él prefiere cantar su fe y, para ello, vuelve al pasado.

Algunos años más tarde, en la composición «Pulvis es» (de 1878) se dirigía Zorrilla a la «extrema generación de mi madre España», advirtiéndole las posibles consecuencias de la que llama su osadía temeraria. La ciencia, sigue, les engaña y atrae, obligándoles a lanzarse en una loca carrera cuyo fin no conocen:

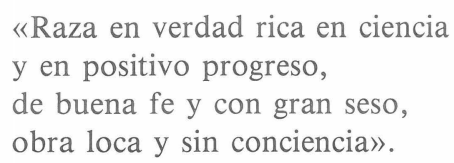

Pasa revista el poeta a los inventos del siglo, que esclavizan, en su opinión y no liberan al hombre. El ser humano nunca podrá alcanzar todos los secretos: la muerte así lo indica. Sólo Dios nivela el paso de la vida a la muerte; sólo Él posee el último secreto:

$$
\begin{aligned}
& \text { «siglo que a todo te atreves, } \\
& \text { y que, del progreso en alas, } \\
& \text { dices que todo lo igualas } \\
& \text { porque todo lo remueves, } \\
& \text { la ley de Dios por ley toma: } \\
& \text { toma de Dios el nivel, } \\
& \text { y el orgullo humano doma } \\
& \text { nivelándole por él». }
\end{aligned}
$$

Este poema es un homenaje, en palabras del mismo Zorrilla, «al agregio poeta castellano Gaspar Núñez de Arce», cuyo eco se advierte a lo largo de toda la composición. Es una de las que pueden ser consideradas «realistas» por su contenido filosófico y su tono expresivo. El poeta se asocia a Núñez de Arce en la finalidad del poema:

22 En Poesías, edición de Narciso Alonso Cortés, citada, págs. 57, 60 y 63. 
«Gaspar, los que pretendemos

difundir la idea en tomos,

$$
\text { ... } 23 \text {, }
$$

lo que no deja de resultar llamativo en un autor que niega que la lírica deba contener ideas ni enseñanzas.

Zorrilla prefiere su vieja poesía basada en la tradición, y que defiende la fe, la virtud y el patriotismo, a la realista, que se deja perder por el progreso y la ciencia. A partir de 1866, un considerable número de sus nuevas obras son leyendas. Éstas le reportarán muchos y rendidos aplausos.

La pugna ciencia-espíritu está en el fondo de una de las polémicas más características y prolíficas de la segunda mitad del XIX: la entablada sobre el tema de la muerte de la poesía, como una forma de espiritualidad, a manos del progreso y la ciencia. Muy unida a ésta surge la del enfrentamiento prosa-verso: los hombres del momento pensaron que tal vez no era la poesía sino la forma poética, el verso, la que habría de morir. La prosa se convertía, así, en la expresión idónea de la nueva época ${ }^{24}$.

Alude en repetidas ocasiones Zorrilla al «estéril positivismo» que destruye el misterio, la naturaleza,..., las fuentes mismas de la poesía (tal y como él la entiende). Sobre este tema es interesante la composición «Los gnomos de la Alhambra (poema fantástico)», contenida en el libro Gnomos y mujeres. De tono narrativo, al estilo de las leyendas, fue escrita como apéndice del nunca concluido Granada. Poema oriental (1852). El poeta siempre manifestó especial interés por la capital andaluza, a la que consideraba cuna riquísima de tradiciones y leyendas, símbolo de la victoria de la fe y, por su belleza y su historia, de la poesía misma. En el poema, la irrupción del progreso entre las ruinas de la Alhambra acaba con toda la poesía.

El texto se abre con una invocación a Granada, seguida de la historia de la Alhambra desde su construcción hasta los años mismos en que Zorrilla escribe. En los fragmentos «La ronda de los gnomos» y «El himmo de los gnomos» entabla el poeta diálogo con los seres maravillosos que la pueblan y que durante la noche inician su danza.

Crea Zorrilla un ambiente fantástico, maravilloso e irreal. Por sus metáforas sensoriales y la utilización del simbolismo musical podría ser calificado de modernista. En medio de ondinas y ninfas, de trasgos y duendecillos, de una Granada convertida por Aláh en «reina de las flores», «de árabes palacios labrados con encajes» y «cármenes regados por fuentes de marfil», de una Alhambra en la que leyenda e historia se confunden, hace su irrupción el progreso:

23 «Pulvis es» se publicó en Revista Contemporánea en 1878. Citamos por la edición de Poesías de Narciso Alonso Cortés, págs. 143, 147-48 y 149.

24 El tema de la muerte de la poesía se discutió en el Ateneo de Madrid durante el curso 1873-74. Con posterioridad a esta fecha, entablaron polémicas sobre el mismo Juan Valera y Ramón de Campoamor, por un lado, y Leopoldo Alas «Clarín» y Gaspar Núñez de Arce, por otro. Sólo citaremos aquí un interesante ensayo de consideración general en torno al concepto de progreso, muy útil para calibrar su importancia en el siglo XIX. Robert Nisbet: Historia de la idea de progreso, Barcelona, Gedisa, 1981. 
«iDelirios de mi vieja poesía!

Ya se fueron.-Volvamos a la tierra.

La Alhambra en este siglo de las luces

no puede continuar en las tinieblas.

Ya la electricidad, hija del rayo

a los rincones más oscuros lleva

con la vívida luz de sus fanales

la luz de la divina inteligencia:

hoy la electricidad, que con el rayo

tierra y mar en segundos atraviesa

ya habla con los antípodas, suprime

las distancias, el tiempo y las fronteras.

Hoy el vapor del hombre más raquítico

pone en las manos del titán la fuerza

y horada el monte, y los abismos salva,

y atrás los ríos, si le estorban, echa».

Las consecuencias del progreso no son positivas para la poesía ni tampoco para Granada. Sin misterio ni fantasía, a la luz de la ciencia analítica, las ruinas de la Alhambra sólo son piedras, despojos de un pasado que el presente desprecia. Pero, además, el avance científico tampoco ha ayudado al hombre:

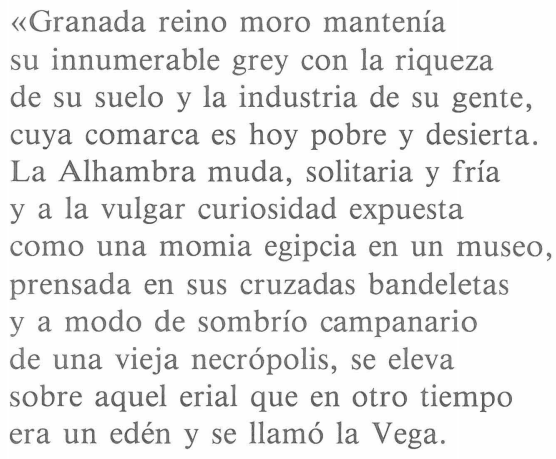

Termina Zorrilla criticando el mal gobierno de aquellos que derrochan el caudal público en «sostener aparatosas fiestas» y no construyen ciudades, canales, huertos o acequias. Ni el progreso ni el liberalismo han ofrecido resultados positivos. La caída en la vulgaridad y el prosaísmo de la poesía no son más que signos, en el marco del «tiempo nuevo», para Zorrilla. En uno de sus más citados poemas de crítica social: «La ignorancia», todo el sistema político es duramente criticado:

25 Todas las citas corresponden a las págs. 74 y 75 del ya citado Gnomos y mujeres. En este volumen aparece también ;Granada mía! Lamento muzárabe, poema escrito con fines benéficos con motivo de los terremotos de Andalucía en 1885. 
«¿Somos doce millones de españoles que no sabemos leer? ¿Sí? ¡Pues por Cristo! ¿qué han hecho en setenta años de progreso y libertad maestros y ministros?» ${ }^{26}$.

La visión desoladora que nuestro autor tiene de la España fin de siglo siempre le anima a volver al pasado, a la España tradicional base de sus leyendas: Dios, patria, y poesía son siempre los ingredientes de su «tiempo viejo».

El poema titulado «El pinar. Estudio nocturno de historia natural» se centra enteramente en el tema de la muerte de la poesía:

«Nuestro siglo no quiere ya poesía:

la poesía muere, Paulina mía: su astro divino se vuelve al firmamento de donde vino»,

dice a Doña Paulina Contreras de Alarcón, a quien se lo dedica. Finge Zorrilla una ficción para explicar a esta señora cómo la máquina destruye la poesía al acabar con su fuente: la naturaleza. Describe una casa situada en un paraje natural, donde todo es reposo hasta que la ciencia y la máquina irrumpen:

«Te he dicho que reposa, que calla todo

en esta selva hojosa: de ningún modo;

todo Paulina,

calla bajo el tumulto que lo domina.

Del vapor al empuje que el hombre guía, la fábrica que ruge, la ferrovía que so los trenes cruje, la gritería, las bocinas, los silbos ... todo es estruendo del progreso que invade nuestra vivienda, son el rumor tremendo de esta leyenda: porque canta la máquina dominadora y de su triunfo víctima la lira llora; al pasar cual relámpago, bajo su rueda la hace añicos la impávida locomotora, y huye espantado el numen, y el hombre queda;

El avance del progreso es metafóricamente representado por el de la sierra que tala los pinares del bosque. La máquina y la sierra:

«avanzan ellas dando con el pinar en tierra, y cuanto poesía en el pinar encierra delante de ellas ceja ... y cejará hasta el mar» ${ }^{27}$.

26 Recogido en la edición de Poesías de Narciso Alonso Cortés, citada, pág. 280.

27 El poema se incluye en la segunda parte de Gnomos y mujeres, obra citada, págs. 141, 151-52 у 153 . 
Este es el presente; por ello el poeta prefiere refugiarse en el «tiempo viejo»: en el ensueño y la fantasía. Una y otra vez tendremos que repetirnos.

Paralelo al tema de la ciencia se sitúa en la época, como señalábamos, el del prosaísmo. Una de las características contradicciones de la segunda mitad del siglo es la proliferación del uso del verso con finalidades muy varias cuando se está profetizando la desaparición de la forma poética. El verso se acerca a la prosa en un intento de sencillez expresiva y se adecua a todos los mensajes. Lo que en la mayor parte de los autores degenera en prosaísmo respondía a un intento consciente por parte de algunos poetas realistas de crear una poesía alejada de todo dialecto poético, avanzando hacia la lírica moderna. Advirtamos que este deseo de sencillez no presupone un menosprecio del verso: Campoamor, que quería escribir con las mismas palabras que pensaba y hablaba todo el mundo ${ }^{28}$, es un defensor acérrimo del verso frente a la prosa.

Zorrilla entiende que la poesía realista es un amasijo de prosa y verso. Tanta filosofía y tanta enseñanza a través de la composición poética ha conducido a que el público mismo pierda interés por ella. Comentaba, en 1867, a Pedro Antonio de Alarcón con motivo de la edición de El drama del alma:

«Mi querido Pedro: los versos que anteceden y van a seguir a esta prosa, serían probablemente música celestial para la mayor parte de los lectores de esta sociedad positivista y calculadora, para la cual nos toca escribir. Me dicen que ya los versos no son letras que corren en el mercado de nuestra patria; y así debe ser, pues los veo impresos como prosa en los periódicos, ...» ${ }^{29}$.

Si los realistas negaban la falacia de la existencia de temas poéticos, Zorrilla piensa que la lírica «no debe descender» a tratar ciertos temas. En los varios textos que lee con motivo de su coronación en Granada, en 1889, identifica su poesía con el himno de la naturaleza que sólo Dios puede inspirar; su lenguaje no puede sino tratar de acomodarse a tan alta inspiración:
«Como al ave, al nacer, me dijo - icanta!
y a impulso de la fe que en mí se encierra
arrancada la voz de mi garganta,
y como el fénix sin cesar cantando
voy mi fe por la propia y por la extraña,
y como el fénix moriré entonando
mi canto funeral en la montaña» ${ }^{30}$.

Este canto a Dios, este himno de la naturaleza (que luego encontraremos en Salvador Rueda), no podía expresarse más que en verso. Los versos no son la poesía, como el público y muchos autores piensan, advierte Zorrilla, pero es el verso el signo más evidente de su dignidad:

28 Véase el capítulo II de su Poética, citada.

29 La carta figura en «El comentario de un loco», dentro de El drama del alma. Algo sobre México y Maximiliano, Burgos, Imp. de D. T. Arnaiz, 1867, pág. 26.

30 De «Est Deus in nobis», en Coronación..., citada, pág. 34. 
«¿Que los versos no son la poesía?

No: pero son su vestidura regia:

son de su jerarquía el atributo,

la pedrería son de su diadema,

de su manto real son los armiños:

la poesía por el verso es Reina» ${ }^{31}$.

El uso de términos coloquiales o filosóficos —esa jerga naturalista y obscena, como la califica en ocasiones- está pervirtiendo el verso, haciéndole perder su calidad de expresión, reservada sólo a ciertos asuntos, opina el autor. Reclama, pues, Zorrilla la vuelta a un lenguaje poético propio, del que el verso sería el vehículo idóneo, rechazando la revolución que en este terreno estaban llevando a cabo los realistas. Si bien este tema se repite a lo largo de su obra, es en los fragmentos de Mi última brega, en la que arremete frontalmente contra la nueva poesía, donde encontramos mejores ejemplos.

Proyecta Zorrilla este libro (del que luego sólo se publicaron fragmentos dispersos en diferentes lugares) como una respuesta a aquellos críticos que se burlaban de él y le acusaban de refugiarse en su «tiempo viejo» porque no podía ni sabía escribir al modo trascendental y realista. Escribe el poeta a Esteban López Escobar sobre esta obra:

«Ya puedes tú figurarte lo que será el libro. Ya estoy harto de hacerme el tonto y pasar por tal.

El verso es una grande arma cuando se domina como yo, y no quiero que crean mis contemporáneos que no vi ni supe lo que pasaba en el mundo en que vivo» ${ }^{32}$.

Luego, como señalábamos, la actitud humilde, el refugio en el pasado es totalmente deliberado por parte del autor, que no se siente inferior al «tiempo nuevo» sino que, por el contrario, y confiado en ese dominio del verso que le llevó a triunfar en los escenarios de los teatros de España con sus lecturas públicas, se considera superior a él en algunos aspectos. Escribía en uno de los fragmentos de Mi última brega:

«No hay cosa ya peor vista
que andar contra la corriente:
hoy es realista la gente
y voy a echarme a realista» ${ }^{33}$.

Quiere Zorrilla demostrar lo fácil que es componer esta nueva poesía: sólo hay que poner la prosa en verso, indica ridiculizando a los autores que desprecian su actitud de mantenimiento del pasado:

31 «Discurso pronunciado en la R.A.E.», citado.

32 Zorrilla comentador póstumo de sus biógrafos, citado, pág. 165. La carta está fechada el 10 de diciembre de 1887.

33 Mi última brega. Los rincones de Valladolid (1888), recogido por Narciso Alonso Cortés en su edición, pág. 205. Se trata del primer fragmento del libro que habría de llevar este título. 


\begin{abstract}
«De hoy en la declinación decadente y bizantina, la poesía divina está aguantando un ciclón. Hoy los versos se desdeñan por más prácticas conquistas; filósofos y realistas contra ellos la lid empeñan.

El verso cae en el desprecio porque hoy rompe toda valla, y se embriaga y se encanalla en poder del vulgo necio. Versos no son poesías, y van en sentido inverso cuando se escriben en verso vulgares majaderías: y escribir en verso ideas estúpidas y vulgares, es como incensar altares con tufo y humo de teas. El verso es el rico engarce de los idiomas del cielo:
\end{abstract} .) 34

Recuerda el poeta que el verso es el vehículo utilizado en los libros sagrados y el que usan, dice, los ángeles para cantar a Dios. Al final, el guiño burlón:
«Pero, en fin, si ya en el día por vieja se desarraiga y es forzoso que caiga por tierra la poesía, yo me echo con ella atrás aunque en ella soy maestro: mas si prescindir del estro puedo... ¡del verso jamás!
Si por hastío o enojo echáis ya el verso a la calle, yo, dondequiera que le halle, como le halle, le recojo. ¡Fuera, pues, la poesía! y pues el verso desciende ya hasta el mercado y se vende, allá va mi mercancía» ${ }^{35}$.

34 Ídem, págs. 212 y 213.
35 Ídem, pág. 215. 
El verso para Zorrilla era, realmente, un instrumento fundamental. Como él mismo reconoce, en sus últimos poemas lo principal es la musicalidad. El contenido apenas tiene importancia, lo que entendemos perfectamente si tenemos en cuenta cuál era su principal cauce de difusión: la lectura en alta voz y con acompañamiento de instrumentos musicales ${ }^{36}$.

Salva el poeta vallisoletano a una serie de autores en su crítica a la poesía realista: Núñez de Arce, Ferrari, Leopoldo Cano, paisanos suyos; Campoamor, Sellés. En su opinion, el extremo más degradado de la poesía prosaica o de la prosa puesta en verso, que es para él el realismo, lo constituye la poesía festiva:

$$
\begin{aligned}
& \text { «El verso que anda a pie, que coge barros, } \\
& \text { fuma, se embriaga y riñe en las plazuelas, } \\
& \text { no es el hijo de Apolo y de las Musas, } \\
& \text { es un rufián de raza gitanesca» }{ }^{37} \text {. }
\end{aligned}
$$

Este desprecio a la poesía festiva se extiende a la zarzuela («zarzuelas sin música y sin poesía»), los toros, «los sonidos de gañotillo, los meneos de lupanar y los salvajes pataleos de lo que se llama cante y baile flamenco», «el gárrulo ruido de discursos»,..., en definitiva, los signos de la decadencia cultural y social del país. Entresacamos estas citas del prólogo de El cantar del romero: en vista de la situación, explica el poeta, decide irse a Asturias, cuna de tradiciones, para reencontrarse con la poesía y poder escribir ${ }^{38}$.

En esta vulgarización del verso radica, en opinión de Zorrilla, el creciente desinterés por la poesía que muestra el público; lo que debe entenderse rectamente: a partir del romanticismo se produce un aumento del público lector de la misma. La acusación del poeta indica que no es por la poesía (tal y como él la concibe) sino por la que él llama prosa puesta en verso por la que hay interés. El público también se ha vulgarizado.

4. Si bien en algunos momentos Zorrilla manifiesta dudas sobre la oportunidad de su poesía, hasta en la última de sus composiciones se mantendrá fiel a sus principios. En «La ignorancia» (compuesta en 1892 aunque publicada póstumamente) indica la sinceridad de toda su obra. Se refiere, en concreto, a su patriotismo (su «españolismo», como él lo llama, utilizando un término del que tambien gustará Rueda más tarde). En este poema se propone limpiar «de mi patria la faz». Zorrilla que estuvo siempre en desacuerdo con la filosofía positivista do-

36 Narciso Alonso Cortés cita en su biografía del poeta una conversación entre éste y el francés Boris de Tannenberg en 1887. Dice Zorrilla: «Yo he renovado completamente en España el arte de leer los versos... He creado una especie de melopea con acompañamiento de violín y de violoncello en sordina, cuyo efecto es pasmoso en el verso español... El valor literario es casi nulo, pero está escrito para hacer ver mis cualidades de lector; hay de todo un poco». Zorrilla. Su vida y sus obras. Tomo III, Valladolid, Imp. Castellana, 1920, pág. 166.

37 «Discurso pronunciado ante la R.A.E.», citado.

38 El cantar del romero. Leyenda en verso, Barcelona, Admon. Sociedad de Crédito Intelectual, 1886, págs. 7 y 8 . 
minante en el siglo, no perdió nunca de vista la realidad. Por su actitud crítica ha sido relacionado con Antonio Machado ${ }^{39}$. Es así como la obra última zorrillesca, aunque de escasa calidad, incorpora los recursos y temas más variados y, como si se tratase de un gesto irónico más del poeta, en su poesía de recuerdo y de pasado pueden extraerse rasgos de la lírica futura.

39 Véase la introducción de Gregorio Torres Nebrera a su Antología poética de José Zorrilla, Barcelona, Plaza y Janés, 1984, especialmente págs. 34 y 35. 